\title{
The Changing Characteristics of the Glaciers of Geiqu Basin during 1978-2010
}

\author{
Peng Gong \\ College of Geography and Environment Science, Northwest Normal University, Lanzhou 730070, \\ China \\ gongpeng628@163.com
}

Keywords: Glacier; Ice reserves; Spatio-temporal changes; Geiqu basin

\begin{abstract}
Glaciers are sensitive indicators of climate change. Spatial-temporal variations of glaciers have been analyzed in the Geiqu basin through employ the technique of geographic information based on two glacier inventory data. Some conclusions can be drawn as follows. (1) Currently, glaciers of Geiqu basin concentrated distribute in the North Slope with the height between 5900 $6000 \mathrm{~m}$. The glaciers with the area of less than $0.5 \mathrm{~km}^{2}$ are the most developed and the ones with the area of above $2 \mathrm{~km}^{2}$ are given priority to (79.35\%). The glacier reserve is $12.5 \mathrm{~km} 3$. During 1978 to 2010, the glaciers of the basin showed retreat trend. The reserves declined by $16 \%$. The glaciers with the area between $0.1 \sim 0.5 \mathrm{~km}^{2}$ and the area between $2 \sim 5 \mathrm{~km}^{2}$ had the most significant retreat. (2) When the end of the glacier gets into the lake, glacier has a higher sensitivity to climate change and an amplification effect on the related feedback. When such glaciers are in intense melting period, leaking water lubricates sled which causes a large scale collapse. The occurrence probability of the ice lake outburst flood is larger than the situation when the end of the glacier does not into the lake, which should be given more attention.
\end{abstract}

\section{Introduction}

Cryosphere and atmosphere, hydrosphere, lithosphere and biosphere constitute the earth surface and the five spheres of climate system. The interactions of cryosphere constitute the complex system of global change [1-3]. Due to the high reflectivity to solar radiation and its own huge phase change latent heat, cryosphere has important influence to the surface energy balance, water cycle, sea level change, atmosphere and ocean circulation, and has significant feedbacks to the climate, which is a sensitive indicator of the climate change of different time and space scales [4-7]. Therefore, under the background of increasing global warming, the time and space variation characteristics and the impact of cryosphere are causing unprecedented attention of science community $[7,8]$.

China has the most developed mountain glaciers in mid-low latitude areas in the world. According to the revised Chinese glacier catalog statistics results, there were 48773 glaciers during the 1960s 1980s covering an area of $61936.97 \mathrm{~km} 2$, which ranked only after Canada and the United States [9-13]. At present, in our country, there are designated observation fields at only a handful of glaciers. Academic knowledge of glacier changes of time and space is mainly based on the glacier catalog data. Since glaciers are widely distributed in the areas with high altitude or high latitude with poor natural conditions and few people, most of the catalog data is interpreted based on topographic map and remote sensing image. The data which can be used in a wide range of glacier interpretation is less (ordinary optical remote sensing image are greatly influenced by the weather and some are bad, which leads to poor image quality), the quantity of people with rich glacier remote sensing experience is limited, and the resources costs are greatly, so massive and systematic catalog data of glaciers and ice lakes are only one or two periods. The time interval of the benchmark videos and images used for cataloging is relatively chaos which is difficult for the systematic understanding to the spatial and temporal variation of glaciers. Based on the glaciers catalog data of two periods, this article conducts systematic research to Geiqu basin glaciers which is helpful to understand the overall spatial and temporal variation characteristics of glaciers of the 
basin.

\section{Research Area}

Geiqu basin is located in the north slope of the Himalayas, affiliated to Pengqu river basin, which is between $2750^{\prime} \sim 2810^{\prime} \mathrm{N}, 8750^{\prime} \sim 8809^{\prime} \mathrm{E}$. Geiqu basin covers an area of $513.79 \mathrm{~km}^{2}$. For administrative divisions, Geiqu basin is located in County Dinggyê, Shigatse of Tibetan Autonomous Region of China. Geiqu river flows to Yeru Zangbo, the tributary of Yarlung Zangbo river with the total length of $37.18 \mathrm{~km}$ (Fig. 1). Geiqu basin is located in the middle Himalayan ridge belt where the terrain has large wavy with high south and low north. The average elevation is $5752 \mathrm{~m}$. This area is typical cold climate. Modern glaciers in the basin are widely developed with not only a large quantity of ancient glacial till, but also constantly forming modern moraines. Glacial till are gravel mixed coarse clastic substance with poor sorting characteristics. The ancient glacial till is mostly cementation or half cementation with deep weathering degree and a role in soil. Recent glacial till is in loose state and the degree of differentiation is shallow. In the basin, the annual average temperature is $2{ }^{\circ} \mathrm{C}$, the average temperature in January is $-8{ }^{\circ} \mathrm{C}$, extreme minimum temperature on average is $-27{ }^{\circ} \mathrm{C}$, the average temperature in July is $12{ }^{\circ} \mathrm{C}$, extreme maximum temperature on average is $18{ }^{\circ} \mathrm{C}$. By the block of Himalayas, the precipitation in the basin is less and seasonal variation characteristic is obvious. More than $85 \%$ of rainfall concentrates in the middle of June to early September.

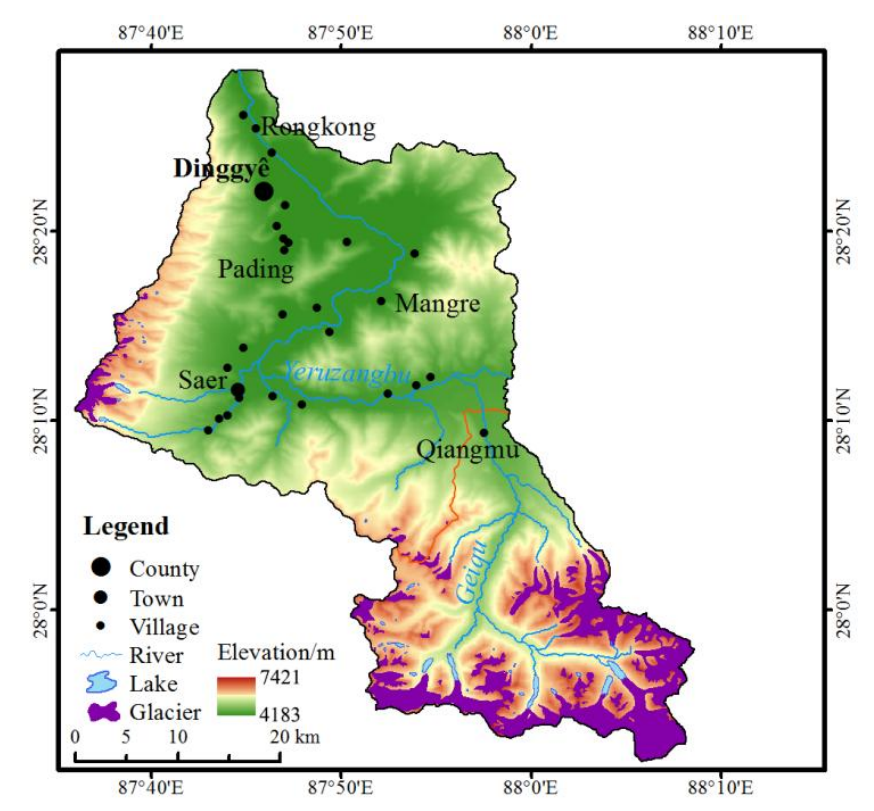

Figure 1. The study area

\section{Data}

The glaciers catalog data of Geiqu basin of two periods is obtained from "Resources survey and change of China's glaciers" project team of the special basic work for the Ministry of Science and Technology and ICIMOD.

\section{Results and Analysis}

The first glacier catalog results show that in 1978 there were 113 developed glaciers in Geiqu basin with a total area of $158.3 \mathrm{~km}^{2}$. The average glacier area was $1.40 \mathrm{~km}^{2}$. The largest glacier area was $30.64 \mathrm{~km}^{2}$, of which the glaciers with the area between $0.1 \sim 0.5 \mathrm{~km}^{2}$ are the most developed, 
accounting for $55.75 \%$ of the total quantity of glaciers, and the total area is given priority to the glaciers with the area of more than $2 \mathrm{~km}^{2}$, accounting for more than $65.41 \%$ of the total area of glaciers. The second glacier catalog results show that in 2010, there were 95 developed glaciers in Geiqu basin, reducing 18 comparing to that of 1978 with the reducing rate of $15.93 \%$ with total area of $131.27 \mathrm{~m}^{2}$. The average glacier area was $1.38 \mathrm{~km}^{2}$. The largest glacier area was $28.37 \mathrm{~km}^{2}$ reducing $27.03 \mathrm{~km}^{2}$ comparing to that of 1978 with the reducing rate of $17.08 \%$. The average annual rate of the glacier is $0.84 \mathrm{~km}^{2} \cdot \mathrm{a}^{-1}$. Glacier change is a result of the combined actions of regional climate and local topography. The area, quantity, elevation, toward of glaciers are analyzed systematically as follows.

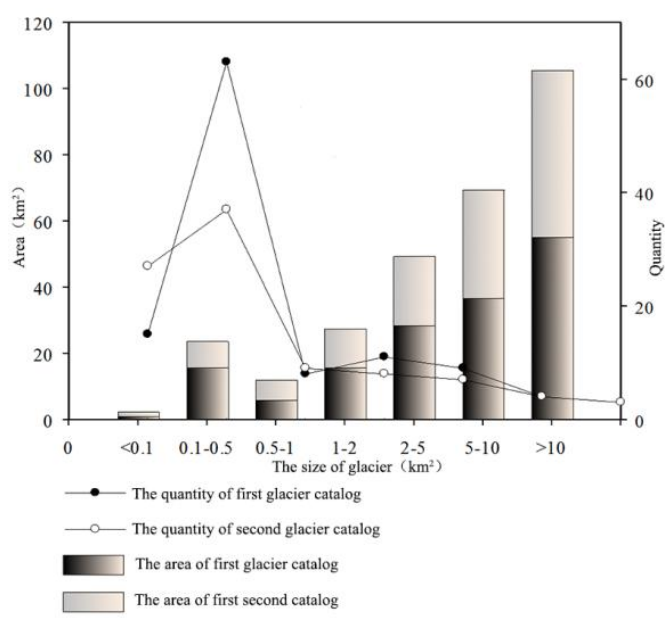

Figure 2. Change of quantity and area of glaciers in Geiqu basin

Glacier Area and Quantity Change. Fig. 2 shows the area and quantity change characteristics of glaciers with different sizes of Geiqu basin. Apparently, the quantity of the glaciers with the area between $0.1 \sim 0.5 \mathrm{~km}^{2}$ has the largest change, which changed from 63 of 1978 to 37 of 2010 with the reducing rate of $41.27 \%$. Although the total quantity of the glaciers reduced the most which was from $63(55.75 \%)$ of 1978 to $37(38.95 \%)$, they are the most developed in the basin. The quantity of the glaciers with the area less than $0.1 \mathrm{~km}^{2}$ is smaller than the quantity of that with the area between $0.1-0.5 \mathrm{~km}^{2}$. The quantity of glaciers increased from 15 of 1978 to 27 of 2010 , increasing 12 with not obvious area change which is from $1 \mathrm{~km}^{2}(0.63 \%)$ of 1978 to $1.33 \mathrm{~km}^{2}(1.01 \%)$ of 2010 with the increasing quantity of $0.33 \mathrm{~km}^{2}$.

The quantity of the glaciers with the area between $0.5 \sim 1 \mathrm{~km}^{2}$ shows weak increase trend which is from 8 to 9 and the area increases only $0.03 \mathrm{~km}^{2}$. The quantity and the area of the glaciers with the area between $1 \sim 2 \mathrm{~km}^{2}$ and $2 \sim 5 \mathrm{~km}^{2}$ show reduce trend. For the former, the quantity reduces from 11 to 8 , reducing $27.27 \%$ and the area reduces from $15.57 \mathrm{~km}^{2}$ to $11.84 \mathrm{~km}^{2}$, reducing 3.73 $\mathrm{km}^{2}(23.96 \%)$. For the later, the quantity reduces from 9 to 2 and the area reduces $7.44 \mathrm{~km}^{2}$

$(26.21 \%)$. The total quantity of the glaciers with the area between $5 \sim 10 \mathrm{~km}^{2}$ and over $10 \mathrm{~km}^{2}$ remains steady (which are 4 and 3). For the former one, the total area reduces from $36.67 \mathrm{~km}^{2}$ to $32.76 \mathrm{~km}^{2}$, reducing $3.91 \mathrm{~km}^{2}(10.66 \%)$, and for the later one, from $55.10 \mathrm{~km}^{2}$ to $50.45 \mathrm{~km}^{2}$, reducing $4.65 \mathrm{~km}^{2}(8.44 \%)$. Although the area of both the two tends to reduce, the total area of them accounts more than half of the total area of the basin glacier, and the proportion of the total area accounting for the basin glacier increases from $57.97 \%\left(91.77 \mathrm{~km}^{2}\right)$ of 1978 to $63.39 \%$ $(83.21 \%)$, which suggests that small glaciers are more sensitive to the change of the surrounding environment.

It is found from the further analysis of the two glacier catalog data of Geiqu basin that there are 19 glaciers of the ones with the area between $0.1 \sim 0.5 \mathrm{~km}^{2}$ are listed into the scale of the ones with 
the area less than $0.1 \mathrm{~km}^{2}$ in the second catalog data due to melting, in which one is divided into two. There are 3 glaciers of the ones with the area between $0.5 \sim 1 \mathrm{~km}^{2}$ are listed into the scale of the ones with the area between $0.1 \sim 0.5 \mathrm{~km}^{2}$ in which two are separately divided into two and there are 2 glaciers of the ones with the area between $1 \sim 2 \mathrm{~km}^{2}$ and one with the area between $2 \sim 5 \mathrm{~km}^{2}$ are listed into the scale of the first due to melting.

Above all, the glaciers with the area less than $0.5 \mathrm{~km}^{2}$ of Geiqu basin are the most developed and the glaciers with the area greater than $2 \mathrm{~km}^{2}$ are given priority to $(79.35 \%)$. During $1978 \sim 2010$, the glaciers with the area less than $0.1 \mathrm{~km}^{2}$ and the area between $0.5 \sim 1 \mathrm{~km}^{2}$ are increased slightly, other scales of glaciers are melting, in which the ones with the area between $0.1 \sim 0.5 \mathrm{~km}^{2}$ and the area between $2 \sim 5 \mathrm{~km}^{2}$ have the most significant melting trend.

Glacier Elevation and Toward Change. Divide glacier data with $100 \mathrm{~m}$ mesh and find out each grid elevation. The statistical analysis of the glacier area shall be done according to the interval of every $100 \mathrm{~m}$ elevation. The distribution characteristics of glacier area along with the elevation of the two catalog data of Geiqu basin, which is shown in Fig. 3. As it is seen, glaciers of Geiqu basin concentrated distribution between $5900 \sim 6000 \mathrm{~m}$ and normally distributed as normal distribution. During $1978 \sim 2010$, the glacier area changes were mainly concentrated below $6500 \mathrm{~m}$ and glacier below $6100 \mathrm{~m}$ had the largest area changes with area reduction of $3.97 \mathrm{~km}^{2}(26.54 \%)$. The average glaciers retreat rate was $0.12 \mathrm{~km}^{2} \cdot \mathrm{a}^{-1}$, which was between $6800 \sim 7100 \mathrm{~m}$. The glacier area had a weak not significant increase, which may be related to regional precipitation increase. In addition, the area change of the glaciers between $6000 \sim 6500 \mathrm{~m}$ is much more significant than that between $5300 \sim 6000 \mathrm{~m}$. the area of the glaciers between $6000 \sim 6500 \mathrm{~m}$ reduced $14.89 \mathrm{~km}^{2}(16.43 \%)$ while that between $5300 \sim 6000 \mathrm{~m}$ reduced $10.48 \mathrm{~km}^{2}(19.66 \%)$. The reducing rate of the later one is large than the former one, which is because the area glaciers distributed between $6000 \sim 6500 \mathrm{~m} \mathrm{had}$ a larger area basis than that between $5300 \sim 6000 \mathrm{~m}$.
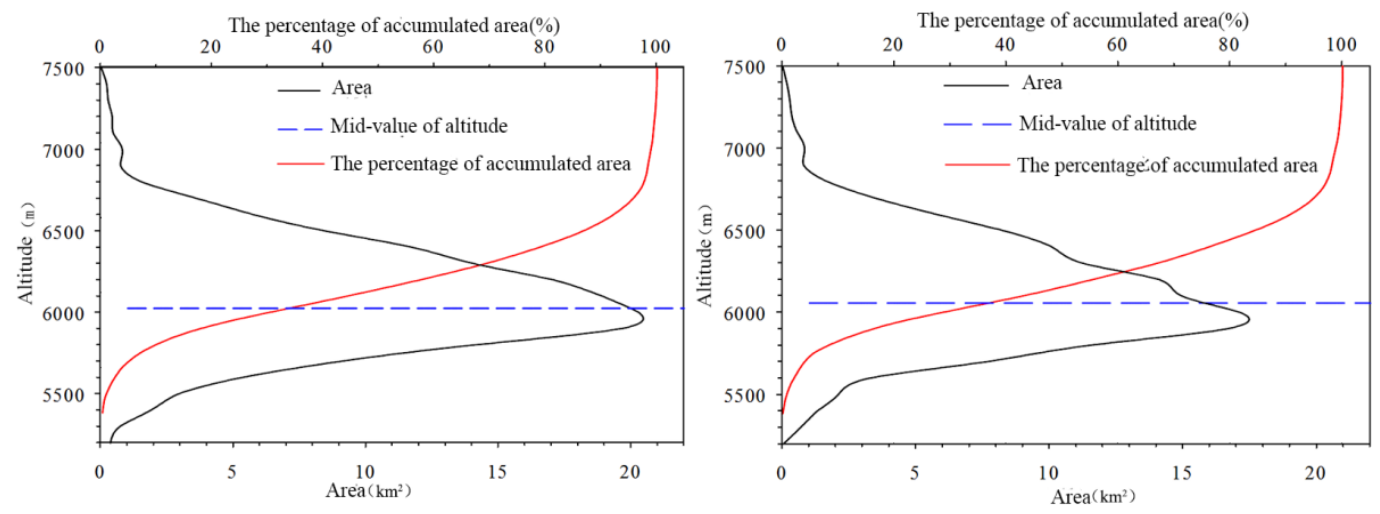

Figure 3. Distribution characteristics of glacier area with the altitude

Carry out systematic statistics to the directions of glaciers according to N, NE, E, SE, S, SW, W and NW. The results are shown in Fig. 4. The size and quantity distribution of glaciers have obvious direction. They are mainly distributed in the north slope of the mountain. According to the first glacier catalog, the quantity of glaciers toward the north and northeast are 22, accounting for $40 \%$ of the total quantity of glaciers. The area of glaciers toward the north is $27.22 \mathrm{~km}^{2}$ and toward the northeast is $49.25 \mathrm{~km}^{2}$, which are more than $48 \%$ of the total area of glaciers. Second, the quantity of glaciers toward the northwest is 13 and the area of them is $34.97 \mathrm{~km}^{2}$, accounting for $22 \%$ of total area. According to the second glacier catalog, the quantity of glaciers toward the north and northeast are $47(49 \%)$ and the area of them are $45 \%$, which still accounts the most. Secondly, the quantity of glaciers toward the west is 11 , ranking the second. The area of them is larger, which is $34.47 \mathrm{~km}^{2}$. Through the comparison of the two glaciers catalog data, the glaciers which are toward 
north and the northeast have the largest glacier area change, reducing $16.78 \mathrm{~km}^{2}$, and the glaciers toward the south have the biggest quantity change, reducing 9. It shows that during 1978 to 2010, glaciers tended to reduce, which showed great difference in different directions, which was associated with facing energy balance. The glaciers which are toward the north and northeast received minimum solar radiation, while the ones toward the south were greatly influenced by the latent heat from solar radiation and precipitation. In addition, the glacier of the glacial lake in the developed period was influenced by glacial lake water heat and the glacial lake had erosion effect on the glacier.
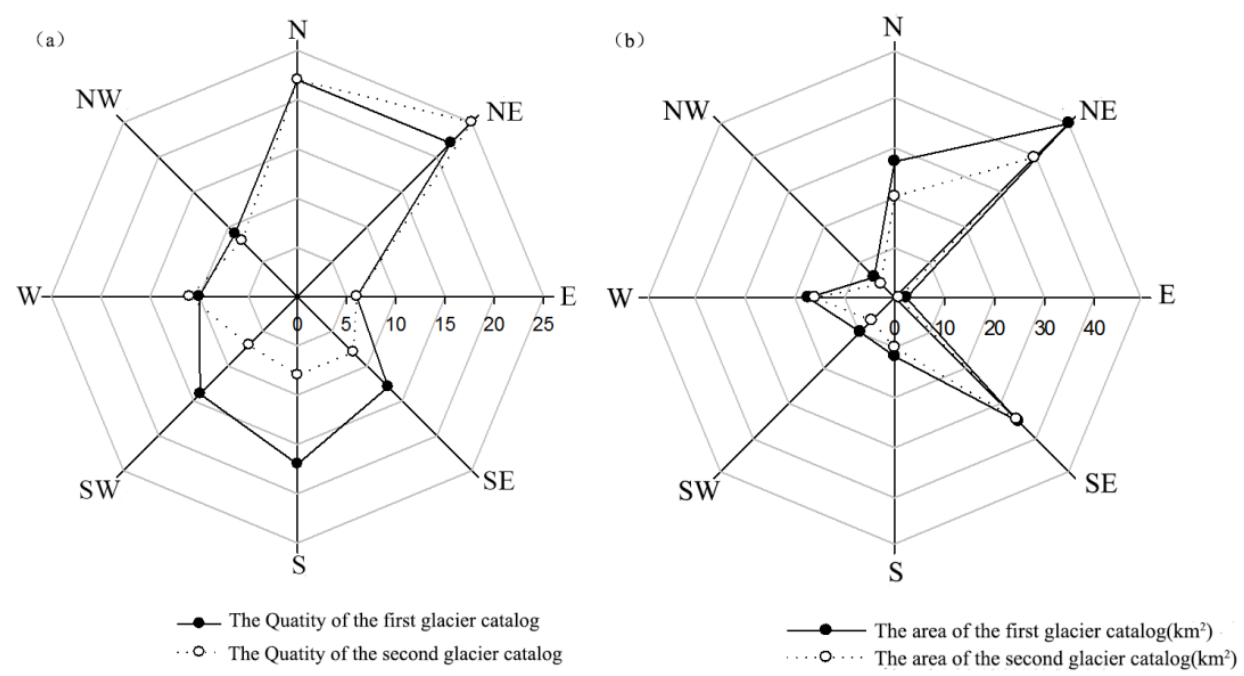

Figure 4. The changes of the quantity and area of each direction of Geiqu bain glacier of the two glaciers catalog

Glacier Reserve Change. Currently, there are two methods to calculate the glacier resource changes. One is to obtain glacier change through the subtraction of the digital elevation model (DEM) of two periods. Its precision depends on the accuracy of digital elevation model. Another one to calculate the absolute reserves of glacier while one to calculate glacier reserve change. As a result of the very strong region of empirical formula, the calculation of the glacier reserve of different areas is different. Restricted by the data of digital elevation model(DEM), this study calculates the ice reserves changes based on the glaciers catalog data of the two times only using the empirical formula which is suitable for the region. At present, most of the empirical formula which is used to calculate ice reserves is based on the index return of the area of glaciers, as shown below:

$$
\mathrm{V}=
$$

In the formula, $\mathrm{V}$ is the ice reserves of glaciers $\left(\mathrm{km}^{3}\right) ; \mathrm{A}$ is the area of glaciers $\left(\mathrm{km}^{2}\right), \mathrm{n}$ and $\gamma$ are empirical coefficients and have large influence on the calculation results.

Using the empirical coefficients put forward by Radić, Hock[14], Grinsted[15] and Liu[16], this study calculates the ice reserves and the changes of Geiqu basin and the results are shown in Table 1. 
Table 1 Glacier volume changes in the Geiqu basin by three methods

\begin{tabular}{ccccc}
\hline $\begin{array}{c}\text { The first glacier } \\
\text { reserve }\end{array}$ & $\begin{array}{c}\text { The second } \\
\text { glacier reserve }\end{array}$ & $\begin{array}{c}\text { Glacier reserve } \\
\text { change }(\mathbf{k m 3})\end{array}$ & $\begin{array}{c}\text { estimate } \\
\text { empirical }\end{array}$ & Formula \\
catalogue $(\mathbf{k m 3})$ & catalogue $(\mathbf{k m 3})$ & & formula & \\
& & & $\mathrm{V}=0.0365 \mathrm{~A}^{1.375}$ & Radic and Hock \\
& 10.3 & 1.95 & $\mathrm{~V}=0.0433 \mathrm{~A}^{1.29}$ & Grinsted \\
12.25 & 10.09 & 1.92 & $\mathrm{~V}=0.04 \mathrm{~A}^{1.35}$ & Liu etc. \\
12.67 & 10.66 & 2.01 & & \\
\hline
\end{tabular}

viously, reserves and the change of Geiqu basin calculated by the three formulas are not consistent, but it is very close to. In ice reserves calculation of the first and the second glacier catalog, empirical coefficient calculation difference is the largest, which are $0.66 \mathrm{~km}^{3}$ and $0.36 \mathrm{~km}^{3}$ respectively. Therefore, reserves of Geiqu basin in 1978 were about $12.5 \mathrm{~km}^{3}$, in 2010 , it reduced about $2.0 \mathrm{~km}^{3}$. From calculation of glacier reserves of the two glacier catalog of the basin, the larger the area of the glacier is, the greater the difference of the empirical formula calculation results will be.

\section{Response to Climate Change of Glaciers of Geiqu Basin}

Regional climate change has a significant effect on spatial and temporal variation characteristics of glaciers and ice lakes. The change of the lake presents unique spatial and temporal variation characteristics according to climate change. Glacier change caused by climate change causes a superposition of linkage effect to glacier change. For further analysis of the characteristics and trend of the change of regional climate, the temperature and precipitation of meteorological stations of Tingri $\left(2838^{\prime} \mathrm{N}, 8705^{\prime} \mathrm{E}\right.$ at an altitude of 4300m) and Lhazê (29 $05^{\prime} \mathrm{N}, 8736^{\prime} \mathrm{E}$ at an altitude of $4000 \mathrm{~m}$ ) are taken as the reference to carry out systematic analysis to the regional climate.

Fig. 5 is the annual temperature variation characteristics of meteorological stations of Tingri and Lhazê in the recent 50 years. Obviously, the annual temperature of the two stations are on the rise. The average annual temperature variation of Lhazê meteorological station is about $2{ }^{\circ} \mathrm{C}$ higher than that of Tingri meteorological station, which is related to the elevation difference of the two meteorological stations. There was a low ebb which was a cold period in 1960s. In 1965, the annual average temperature is negative, and then it began to rise. The annual average temperature rising rate is $0.72^{\circ} \mathrm{C} \cdot \mathrm{a}^{-1}$. By 1971 , the annual average temperature was $2.78{ }^{\circ} \mathrm{C}$. After 1971 , the annual average temperature of the two meteorological stations were in stable upward trend and the annual average temperature increasing rate were respectively $0.03^{\circ} \mathrm{C} \cdot \mathrm{a}^{-1}$ and $0.05^{\circ} \mathrm{C} \cdot \mathrm{a}^{-1}$.

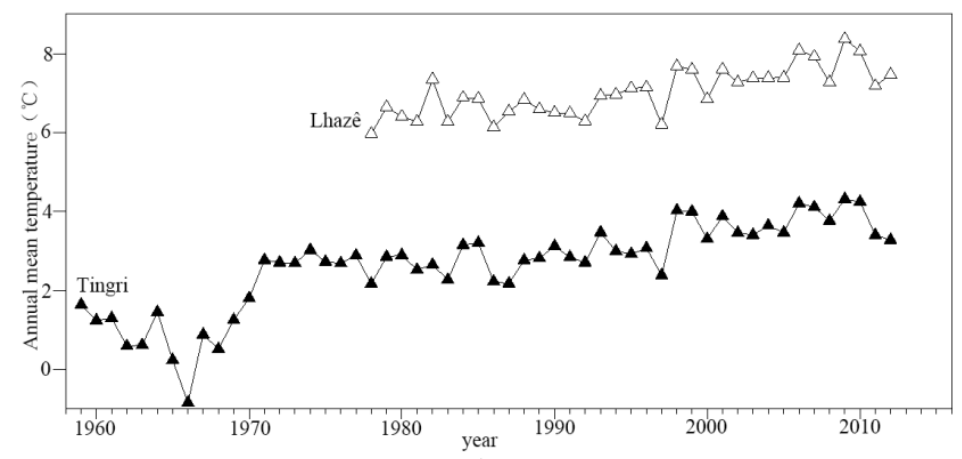

Figure 5. Annual temperature variation characteristics of meteorological stations of Tingri and Lhazê in the recent 50 years 
Fig. 6 is the annual precipitation variation characteristics of meteorological stations of Tingri County and Lhazê County in the recent 50 years. The annual precipitation of both the two meteorological stations show large fluctuations, and tend to increase. The average annual precipitation of Tingri meteorological station was $281.66 \mathrm{~mm}$ from 1959 to 2010 and the precipitation variation during the 53 years is $1.42 \mathrm{~mm} \cdot \mathrm{a}^{-1}$. The average annual precipitation of Lhazê was $327.96 \mathrm{~mm}$ and the precipitation variation is $1.76 \mathrm{~mm} \cdot \mathrm{a}^{-1}$ from 1978 to 2012 .

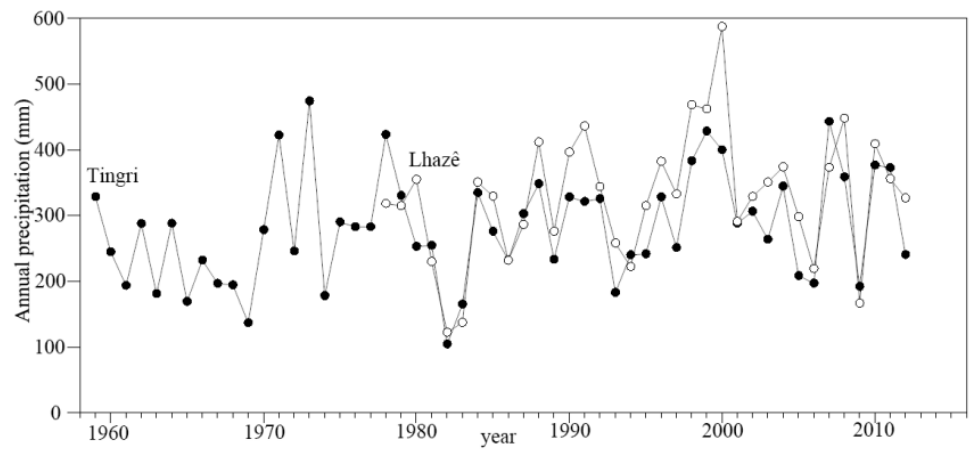

Figure 6. Annual precipitation variation characteristics of meteorological stations of Tingri and Lhazê in the recent 50 years

Above all, the climate of Geiqu basin will be warm and wet. Temperature increasing will cause glaciers melt faster, precipitation increasing will increase the internal temperature of glaciers by means of latent heat transfer, promote glaciers melting. The runoff of Geiqu basin will increase furtherly and the ice lakes of the basin will expand much faster. In addition, when the end of glaciers directly get into a lake, melting glaciers provide space and material sources for frozen lake expansion, and the temperature difference between frozen lakes and glaciers make the ice tongue part of the interface between the glacier and lake rapidly melting, which accelerates glacier retreat[17]. The effect of wind and the lake causes the physical erosion to the glaciers near the water, which then causes part glaciers collapse and melt into the lake, which accelerates the glaciers melting[18]. Therefore, when the end of the glacier gets into the lake, glacier has a higher sensitivity to climate change and an amplification effect on the related feedback. When such glaciers are in intense melting period, leaking water lubricates sled which causes a large scale collapse. The occurrence probability of the ice lake outburst flood is larger than the situation when the end of the glacier does not into the lake, which should be given more attention.

\section{Conclusion}

(1) Currently, glaciers of Geiqu basin concentrated distribute in the north slope with the height between $5900 \sim 6000 \mathrm{~m}$. The glaciers with the area of less than $0.5 \mathrm{~km}^{2}$ are the most developed and the ones with the area of above $2 \mathrm{~km}^{2}$ are given priority to $(79.35 \%)$. The glacier reserve is 12.5 $\mathrm{km}^{3}$. During 1978 to 2010, the glaciers of the basin showed retreat trend. The reserves declined by $16 \%$. The glaciers with the area between $0.1 \sim 0.5 \mathrm{~km}^{2}$ and the area between $2 \sim 5 \mathrm{~km}^{2}$ had the most significant retreat.

(2) When the end of the glacier gets into the lake, glacier has a higher sensitivity to climate change and an amplification effect on the related feedback. When such glaciers are in intense melting period, leaking water lubricates sled which causes a large scale collapse. The occurrence probability of the ice lake outburst flood is larger than the situation when the end of the glacier does not into the lake, which should be given more attention. 


\section{References}

[1] IPCC. Climate Change 2007: The Physical Science Basis. Contribution of Working Group 1 to the Fourth Assessment Report of the Intergovernmental Panel on Climate Change. Cambridge and New York, 2007, 1-18.

[2] Z.C. Xie, C.H. Liu. An Introduction to the Glacier. Shanghai: Shanghai Popular Science Press, 2010, 1-490. (In Chinese)

[3] D.H. Qin, W.J. Dong, Y. LUO. China's Climate and Environmental Change: the Scientific Basis for the First 2012 Volumes. Beijing: China Meteorological Press, 2012, 1-432. (In Chinese)

[4] Y.F. Shi. China's Glaciers and the Environment - Present, Past and Future. Beijing: Science Press, 2000, 1-410. (In Chinese)

[5] M.S. Cao, X. Li, X.Z. Chen, et al. Cryosphere Remote Sensing. Beijing: Science Press, 2006, 1-266. (In Chinese)

[6] UNEP, WGMS. Global Glacier Changes: Facts and Figures. 2008, 1-88.

[7] J.L. Bammer, A.J. Payne. Mass Balance of the Cryosphere: Observations and Modeling of Contemporary and Future Changes. New York: Cambridge University Press, 2004, 1-453.

[8] Y.J. Ding, M. Mu, R.D. Lin. Climate and Environment Changes in China : Volume II 2012 Impacts and Vulnerability. Beijing: China Meteorological Press, 2012, 1-459. (In Chinese)

[9] Z.T. Wang, H.C. Su. Glacier Water Resources Distribution and Its Significance in the World and China. Glaciology and Cryopedology, 2003, 25 (5): 198-502.

[10] Y.F. Shi. A Concise List of Glaciers in China. Shanghai: Shanghai Popular Science Press, 2005, 1-194. (In Chinese)

[11]S.Y. Liu. Glacier Observation and Research Methods. Beijing: Science Press, 2012, 1-211. (In Chinese) (In Chinese)

[12]S.Y. Liu, X.J. Yao, W.Q. Guo, et al. Based on the Present Situation of Chinese Glacier Inventory for the Second Time. Acta Geographica Sinica, 2015, 70 (1): 3-16. (In Chinese)

[13]D.M. Xu, Q.H. Feng. Risk and Lake Outburst Characteristics of the Himalayan Region of Tibet. Acta Geographica Sinica, 1989, 44 (3): 343-352. (In Chinese)

[14]V. Radić, R. Hock. Regional and Global Volumes of Glaciers Derived from Statistical Upscaling of Glacier Inventory Data. Journal of Geophysical Research, 2010, 115, F01010, doi: 10.1029/2009JF001373.

[15]A. Grinsted. An Estimate of Global Glacier Volume. The Cryosphere, 2013, 7: 141-151.

[16]S. Liu, W. Sun, Y. Shen, et al. Glacier changes since the Little Ice Age maximum in the western Qilan Shan, northwest China, and consequences of glacier runoff for water supply. Journal of Glaciology, 2003, 49(164):117-124.

[17]T. Che, X. Li, P.K. Mool, J.C. Xu. Monitoring Glaciers and Associated Glacial Lakes on the East Slopes of Mount Xixabangma from Remote Sensing Images. Glaciology and Cryopedology, 2005, 27 (6) : 801-805. (In Chinese)

[18]J. Gardelle, Y. Arnaud, E. Berthier. Contrasted Evolution of Glacial Lakes Along the Hindu Kush Himalaya Mountain Range Between 1990 and 2009. Global and Planetary Change, 2011, 75(1-2): 47-55. 